This is a post-peer-review, pre-copyedit version of an article published in Chemical Papers. The final authenticated version is available online at: http://dx.doi.org/10.1007/s11696-020-01477-8 


\title{
A comparative study of the effect of organic dopant ions on the electrochemical and chemical synthesis of the conducting polymers polyaniline, poly(o-toluidine) and poly(o-methoxyaniline)
}

Hasan F. Alesary ${ }^{I^{*}}$, Hani K. Ismail ${ }^{2 * *}$, Mohammed Q. Mohammed ${ }^{3}$, Halgurd N. Mohammed ${ }^{4}$, Zaid K. Abbas ${ }^{5}$, Stephen Barton ${ }^{6}$

${ }^{1}$ Department of Chemistry, College of Science, University of Kerbala, Kerbala, Iraq.

${ }^{2}$ Department of Chemistry, Faculty of Science and Health, Koya University, Koya KOY45, Kurdistan Region F.R., Iraq.

${ }^{3}$ Department of Chemistry, College of education for pure sciences, University of Basrah, Basrah, Iraq.

${ }^{4}$ Pharmacy Department, Aynda Private Technical Institute, Erbil- Iraq.

${ }^{5}$ Technical Department, Ducab, DUBAI, UAE.

${ }^{6}$ Kingston University London, School of Life Sciences, Pharmacy and Chemistry, Kingston-Upon-Thames, Surrey, UK.

*Corresponding author: hasan.f@uokerbala.edu.iqＯRCID: https://orcid.org/0000-0002-3116-5145

**Corresponding author: hani.khalil@koyauniversity.org ORCID: https://orcid.org/0000-0001-5407-1806

\begin{abstract}
Electroactive polymers such as polyaniline and its derivatives have many potential applications, but the nature of the dopants can have an adverse effect on their properties. Polyaniline (PANI), poly(o-methoxyaniline) (POMA) and poly(o-toluidine) (POT) have been synthesised using appropriate organic acid dopants (2-naphthalenesulfonic acid and 1,5-naphthalenedisulfonic acid) via electrochemical and chemical polymerisation methods, where the later was achieved at $\mathrm{pH}(1-2)$ in the presence of ammonium persulfate as an oxidant. The effects of the monomers and organic dopants on the physiochemical properties and morphological surface of the polymers were studied by means of Fourier transform infrared spectroscopy, electrical conductivity measurements, thermogravimetric analysis, and scanning electron microscopy (SEM). The above films were also synthesised electrochemically whilst varying conditions such as scan rate, scan number, and in aqueous solution of organic acids using cyclic voltammetry techniques. Cyclic voltammetry experiments have been employed to analyse the growth behaviour and electrochemical stability of films in the background electrolytes (monomer-free). It was found that PANI salts displayed higher doping levels and conductivity while POMA and POT salts were found to show lower conductivity and doping levels, respectively. Furthermore the electrochemical response of films was different in the stability and this may be because of the methoxy $\left(-\mathrm{OCH}_{3}\right)$ and methyl $\left(-\mathrm{CH}_{3}\right)$ groups located at the ortho position of the aromatic ring structure of the monomers (o-methoxyaniline and o-toluidine). The $-\mathrm{OCH}_{3}$ and- $\mathrm{CH}_{3}$ groups have significant steric effects and can reduce to form long chains of polymers, and also decrease conductivity. The SEM showed that the morphologies of the prepared conducting polymers were different, which was associated with the nature and size of the dopant and monomer present in the bath solution.
\end{abstract}


Key words: Conducting polymers, polyaniline, poly(o-toluidine), poly(o-methoxyaniline), dopant ions, chemical and electrochemical polymerisation.

\section{Introduction}

Conducting polymers such as polyaniline and its derivatives (Qu et al. 2020), polythiophene (Bazzaoui et al. 1994), polypyrrole (Omastová and Mičušík 2012), and poly(3,4-ethylenedioxythiophene) (Gruia et al. 2020) are used in a number of fields in industry such as corrosion protection of metals ( (Tseghai et al. 2020), biosensors and gas sensors (Yin et al. 2006), electrocatalysis (Gustafson et al. 2014), electrochromic display devices (Tian et al. 2017), supercapacitors (Deshpande et al. 2013), and in rechargeable batteries (Hong et al. 2020). This is due to their excellent features such as low cost, environmental stability, light weight, and good electrical properties. In addition, they can be prepared easily from their monomers by electrochemical or chemical polymerisation (Hillman et al. 2017; Ismail et al. 2019b). Although there are many applications for conducting polymers, especially in electromechanical and electronics applications, there are certain limitations to their use such as poor electrochemical stability, low conductivity, insolubility in common organic solvents, and their infusibility. Thus, some electroactive polymer structures are difficult to fabricate via electrochemical or chemical methods ( poly(o-methoxyaniline) (POMA), also known as poly(o-anisidine), and poly(o-toluidine) (POT) (the ring substituted with alkyl and alkoxy) are considered a significant family of conjugative polymers and they can be prepared by either chemical or electrochemical polymerisation methods (Mattoso and Bulhoes 1992; Wei et al. 1989). Generally, the chemical polymerisations of aniline, o-methoxyaniline and o-toluidine (Structures of monomers are shown in Fig. 1) are carried out in aqueous/organic or ionic liquid solutions using an oxidant and strong inorganic or organic doping acids (Huang and Wan 1999). By contrast, in the electrochemical method an electrochemical cell is needed, where a thin coating of polymer can be deposited on the surface of a substrate (Alabdullah et al. 2020; Ismail et al. 2019a). In both systems, the polymerisation of the relevant conjugated monomer can be achieved, and charge carriers are produced utilising particular dopants. The conductivity of the resultant polymer occurs as a result of electron transfer through the conjugated structure. However, the choice of appropriate dopant and monomer are important factors in the production of a polymer with good electrical conductivity and processability.

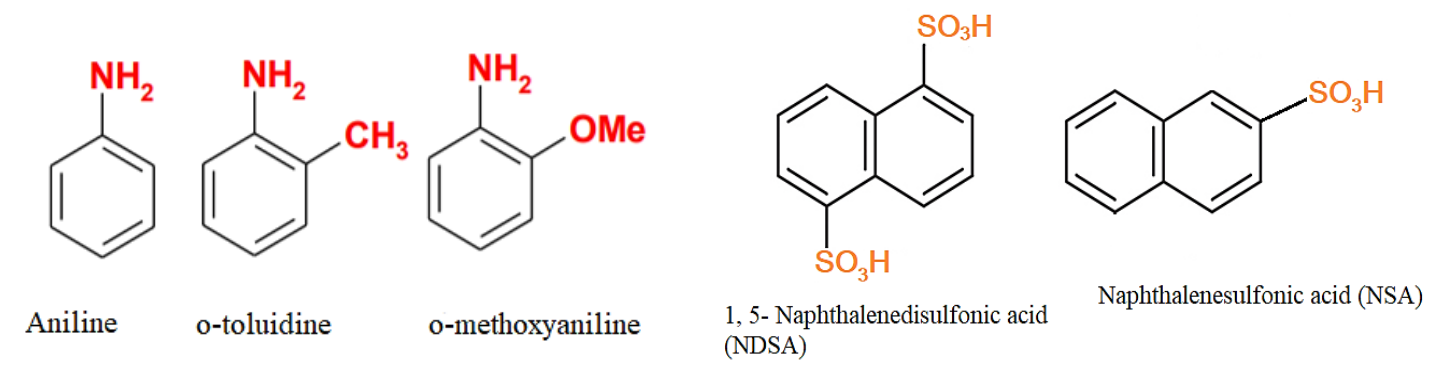

Fig. 1 Structures of monomers and organic dopant ions used in this work. 
In this regard, conducting polymers have been investigated by many researchers in order to optimise properties such as electrical conductivity and electrochemical response without adding fillers (Delvaux et al. 2000). The addition of certain substances directly to the polymer matrix or during the polymerisation process can cause changes to the electrical properties of the polymer. The influence of inorganic and organic acids as dopant ions on the electro/chemical growth, morphology, molecular structure, and the optical and conductivity properties of polyaniline, poly(o-toluidine), poly(o-methoxyaniline) films has been reported (Borole et al. 2004). The type of dopant and thus technique used to prepare the polymer can also have a significant effect on the polymer's properties (Alesary et al. 2018). Therefore, the degree of polymerisation and type of dopant are very important factors as they can affect the charge carriers, morphologies, and conductivity of the polymer, but this relies on the concentration of monomer, polymerisation technique, and kind of dopant species used (Zhang et al. 2005). Thus, the stability of redox reactions is considered to be of particular significance to the polymerisation process (Chujo 2011).

Many researchers have attempted to enhance the quality of conductive polymers and to improve their electrochemical stabilities, but major challenges still remain in this field. Recent studies focus on the use of inorganic acids (hydrochloric acid $(\mathrm{HCl})$, nitric acid $\left(\mathrm{HNO}_{3}\right)$, chloric acid, $\mathrm{HClO}_{3}$ and sulphuric acid $\left(\mathrm{H}_{2} \mathrm{SO}_{4}\right)$ ) as dopant materials in the preparation of conducting polymers(Borole et al. 2002). However, most polyaniline salts doped with small size dopants (i.e., inorganic acids) have low thermal stability, low solubility in conventional organic solvents, and are hazardous materials. In order to overcome these drawbacks, other organic acid dopants can be used instead of $\mathrm{HCI}$ and $\mathrm{H}_{2} \mathrm{SO}_{4}$ and this issue has received less attention in contrast to the inorganic acids. Previous studies reported that the introduction of $-\mathrm{SO}_{3} \mathrm{H}$ in the aniline ring can increase the conductivity and optimise the growth rate for polyaniline compared to other acids, where the reaction rate followed the order: $\mathrm{H}_{2} \mathrm{SO}_{4}$ $>\mathrm{H}_{3} \mathrm{PO}_{4} \approx \mathrm{HF}>\mathrm{HCI}>\mathrm{HNO}_{3}>\mathrm{HClO}_{4}>\mathrm{HBF}_{4}>\mathrm{CF}_{3} \mathrm{CO}_{2} \mathrm{H}$ (Borole et al. 2002). Therefore, in this study, 2naphthalenesulfonic acid (NSA) and 1,5-naphthalenedisulfonic acid (NDSA) (the structures of the NDSA and NSA dopant ions are shown in Fig. 1) were selected as large organic sulphonic acids dopants having $-\mathrm{SO}_{3} \mathrm{H}$ groups as the best anion dopant effecting the growth rate of polyaniline. In addition, the presence of the two sulfonic acid groups in NDSA helps achieve the doping for different polymer chains of the conducting polymer and creates a 3D network structure. In this way, the structure becomes more crystalline, which increases its conductivity, as reported in this paper. For the 2-naphthalenesulfonic acid, the dopant has one proton to dope the polyaniline single chain at one time.

The main purpose of this paper is to study the influence of certain organic sulphonic dopants on the conductivity, thermal stability, morphological characteristics, and electrochemical behaviour of the PANI, POT and POMA polymers. Thus, the effect of the substituted methyl $\left(-\mathrm{CH}_{3}\right)$ and methoxy $\left(-\mathrm{OCH}_{3}\right)$ groups present at the ortho position in PANI on the physicochemical properties of polymer (mentioned above) can further be determined. To the best of our knowledge, this work has not been attempted in previous studies. The first part of this study involved in the preparation of six conducting polymer compounds chemically using two different types of dopants. These compounds are PANI-NDSA, POT-NDSA, POMA-NDSA, PANI-NSA, POT-NSA, and POMA-NSA. Fourier transform infrared (FTIR), thermogravimetric analysis (TGA), and scanning electron microscopy (SEM) were used 
to characterise the various species. The second part involved the preparation of PANI, POT and POMA doped with NDSA and NSA individually via electrochemical methods (cyclic voltammetry). The electrochemical stability of the polymers so prepared were characterised in their monomer-free organic dopant acids. The conductivities of the polymers have been measured for both methods (chemical and electrochemical). The polymer was deposited on the special Pt working electrode (diameter $1 \mathrm{~cm}$ ); for more details, see the conductivity measurements in the results and discussion, and this is considered to be a key point in this study.

\section{Experimental}

\section{Materials}

Aniline, o-toluidine, and o-methoxyaniline monomers were obtained from Sigma Aldrich ( $\geq 99 \%$ ), Ammonium peroxydisulfate (APS) of analytical reagent grade was obtained from Fisher Chemicals (98\%) and used as an oxidant for chemical polymerisation. 1,5-naphthalenedisulfonic acid (NDSA) and 2-naphthalenesulfonic acid (NSA), used as dopants, were obtained from Sigma Aldrich at purities of $97 \%$ and $70 \%$, respectively. All chemical materials and solvents were used as received without further purification.

\section{Chemical polymerisation}

Six samples of polymers were synthesised by separately dissolving $5 \mathrm{ml}$ of each monomer (aniline, omethoxyaniline, and o-toluidine) in $82 \mathrm{ml}$ of $1 \mathrm{M}$ of each organic acid (NDSA and NSA) and stirring for 30 minutes in an ice bath. The ratio of $1 \mathrm{M}$ organic acids to aniline was 0.75 . The oxidant material was ammonium persulfate (APS), where $9.33 \mathrm{~g}$ of this oxidant was placed in the container and dissolved in $100 \mathrm{ml}$ of distilled water. The molar ratio between the oxidant and each monomer was 4:3 (Alesary et al. 2018; Ismail et al. 2019b). The oxidant liquid (APS) was dropped into each of the monomer solutions made previously. The polymerisation process was performed in an ice bath at a temperature of $1-2{ }^{\circ} \mathrm{C}$ with stirring, and the $\mathrm{pH}$ of the bath solution was $1-2$. The colour of the solution started to change to blue 15-20 minutes after adding the oxidant, and then progressively became dark green. In all the experiments, the polymerisation process was performed under the same conditions of use and the reaction time was $4 \mathrm{~h}$. The final compounds were filtered using a Buchner funnel, followed by washing with approximately 2 litres of distilled water followed by acetone, and then dried in a vacuum oven at $50^{\circ} \mathrm{C}$.

\section{Electrochemical polymerisation}

The electrochemical polymerisation was performed by cyclic voltammetry (CV) in a cell with three electrodes using an Autolab PGSTAT20 potentiostat. A platinum (Pt) electrode $\left(1 \mathrm{~mm}\right.$ dia.) and Pt flag (surface area $2 \mathrm{~cm}^{2}$ ) were used as the working and counter electrodes, respectively, with an $\mathrm{Ag} / \mathrm{AgCl}$ reference electrode made from an $\mathrm{Ag}$ wire placed in saturated $\mathrm{KCl}$ solution. The Pt working electrode was polished using $0.3-\mu \mathrm{m}$ alumina paste prior to each experiment. The electropolymerisation was performed using a $0.2 \mathrm{M}$ solution of each monomer (aniline, otoluidine, and o-methoxyaniline) separately in aqueous solution containing various organic acids (NDSA and NSA were used separately; see the legends of figures for each experiment) at $1 \mathrm{M}$ concentrations. The electrode was 
scanned over a potential range from -0.2 to $1.1 / 1.2 \mathrm{~V}$ at a scan rate of $20 \mathrm{mV} \mathrm{s}^{-1}$ for 10 cycles, with all experiments carried out at $25 \pm 2{ }^{\circ} \mathrm{C}$.

After the completion of electrochemical deposition in each experiment, the electrode was disconnected and removed from the monomer electrolyte. Then, each polymer film was rinsed and cycled (10 cycles; $\left.v 20 \mathrm{mV} \mathrm{s}^{-1}\right)$ in the same background electrolyte (monomer-free) at room temperature $\left(25 \pm 2{ }^{\circ} \mathrm{C}\right)$ for characterisation.

\section{Instrumentation}

Fourier Transform Infrared (FTIR) spectroscopy was performed using a Perkin Elmer Spectrum One Fourier transform infrared spectrophotometer over a frequency range of $500-4000 \mathrm{~cm}^{-1}$ with the polymer dispersed in a $\mathrm{KBr}$ disk. The morphologies of the conducting polymers were characterised by scanning electron microscopy (SEM) using a FEI SIRION SEM instrument. SEM analyses were achieved under vacuum $\left(10^{-5} \mathrm{~Pa}\right)$ with an accelerator voltage in the range of 5 to $10 \mathrm{keV}$ due to the polymers being relatively soft materials. Thermogravimetric analysis (TGA) was used to measure the thermal stabilities of the conductive polymers powders in platinum crucibles via a Mettler Toledo 44 TGA/DSC 1 STARe system.

The conductivity of all polymers synthesised by chemical or electrochemical polymerisation was measured by a four-probe method using an APTFE cell. The dry powder polymer was pressed into discs (13 mm diameter) using a compressor (10 tonnes), and the polymer thicknesses measured using a digital micrometer. The conductivity was recorded using a Keithley195 current source and a Keithley197 electrometer controlled via a computer. Finally, the van der Pauw (Banaszczyk et al. 2010) equation (1) was used to calculate the conductivities of the polymers, as follows:

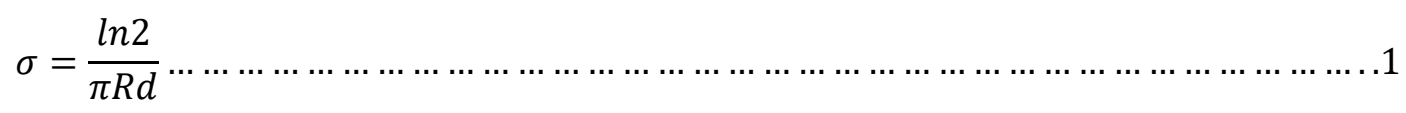

where $\sigma$ represents the conductivity of the polymer (in $\mathrm{S} / \mathrm{cm}$ ), $R$ is the gradient of the current versus voltage graph and $d$ is disc thickness of the polymer.

\section{Results and Discussion}

\section{FTIR Spectroscopy of Polymers Doped with NDSA and NSA}

FTIR spectroscopy was used to analyse polymeric samples that were synthesised from two types of organic dopant ions using 1,5-naphthalenedisulfonic acid (NDSA) and 2-naphthalenesulfonic acid (NSA). Polyaniline, poly(omethoxyaniline) and poly(o-toluidine) were synthesised using chemical polymerisation in this study. Fig. 2a shows the infrared spectra of the main vibrational features associated with PANI-NDSA and PANI-NSA. In the case of PANI-NDSA, there is a small peak at $3210 \mathrm{~cm}^{-1}$ which can be attributed to an $\mathrm{N}-\mathrm{H}$ stretching vibration while the band located at 3435 can be attributed to $-\mathrm{OH}$ groups (which could possibly be from traces of water in the sample). 
The peak at $1558 \mathrm{~cm}^{-1}$ corresponds to a quinoid vibration $(\mathrm{C}=\mathrm{C})$ whilst the peak at $1480 \mathrm{~cm}^{-1}$ indicates a benzoid ring $(\mathrm{C}=\mathrm{C})$ in the PANI structure. The strong band at $1305 \mathrm{~cm}^{-1}$ is due to a $\mathrm{C}-\mathrm{N}$ stretching vibration associated with the benzenoid ring while the peak at $1241 \mathrm{~cm}^{-1}$ corresponds to $\mathrm{C}^{-\mathrm{N}^{+}}$stretching in the conducting PANI, confirming the protonation and the delocalisation of the polymer. In addition, there is a peak at $1135 \mathrm{~cm}^{-1}$ which may represent a C-H in-plane (o/p) bending vibration, whereas the peak at $792 \mathrm{~cm}^{-1}$ can be associated with the C-H out-of-plane vibration. The NDSA and NSA dopant ions in the PANI can be assigned to the band at $1025 \mathrm{~cm}^{-1}$ which corresponds to the $\mathrm{S}=\mathrm{O}$ stretching vibration, whilst the feature located around $704 \mathrm{~cm}^{-1}$ is an $\mathrm{S}-\mathrm{O}$ vibration. Similar characteristic spectra have been observed in the PANI prepared with NSA dopant ions, but the peaks are sharper and of stronger intensity. The above features correspond to those previously reported in the literature (Borole et al. 2006; Huang and Wan 1999).

It is worth noting that the FTIR spectra of the poly(o-toluidine)-NDSA and poly(o-toluidine)-NSA showed more peaks and with higher intensities compared with the PANI conducting polymers. The same characteristic spectra were observed in both polymers (i.e., with NDSA or NSA), but there are small shifts in the locations of various peaks, as highlighted in detail in Fig. 2b. Fig. 2b shows strong peaks at $3449 \mathrm{~cm}^{-1}$ and 3045-3150 $\mathrm{cm}^{-1}$, which can be attributed to $-\mathrm{OH}$ and N-H stretching vibrations, respectively. The bands at $2893 \mathrm{~cm}^{-1}$ in POT-NDSA and at 2912 $\mathrm{cm}^{-1}$ in POT-NSA were due to $\mathrm{C}-\mathrm{H}$ stretching, the bands at $1549 \mathrm{~cm}^{-1}$ were assigned to vibrations associated with quinoid rings $(\mathrm{C}=\mathrm{C})$, while the peak at $1498 \mathrm{~cm}^{-1}$ can be attributed to benzoid ring-related vibrations. It should be noted that the peak at $1383 \mathrm{~cm}^{-1}$ can be assigned to the methyl group adjacent to the benzene ring of o-toluidine (Yalçınkaya et al. 2010). The strong band located at $1095 \mathrm{~cm}^{-1}$ corresponds to the biopolaronic structure (C-H out of plane $\mathrm{o} / \mathrm{p}$ bending) in the conjugated POT-NSA, but this band is extremely weak in POT-NDSA and hence is not observed. The $\mathrm{S}=\mathrm{O}$ stretching and $\mathrm{S}-\mathrm{O}$ vibrations for NDSA and NSA dopant ions in the POT can be assigned to the bands observed at 1039-1029 $\mathrm{cm}^{-1}$ and $759-667 \mathrm{~cm}^{-1}$, respectively. These bands are in agreement with those of chemically synthesised poly(o-toluidine) (Elmansouri et al. 2007; Yalçıkaya et al. 2010).

a)

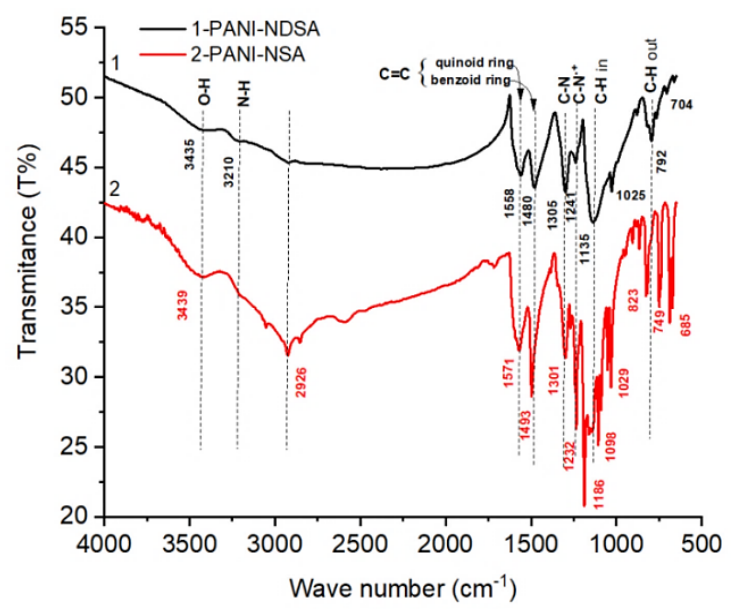

b)

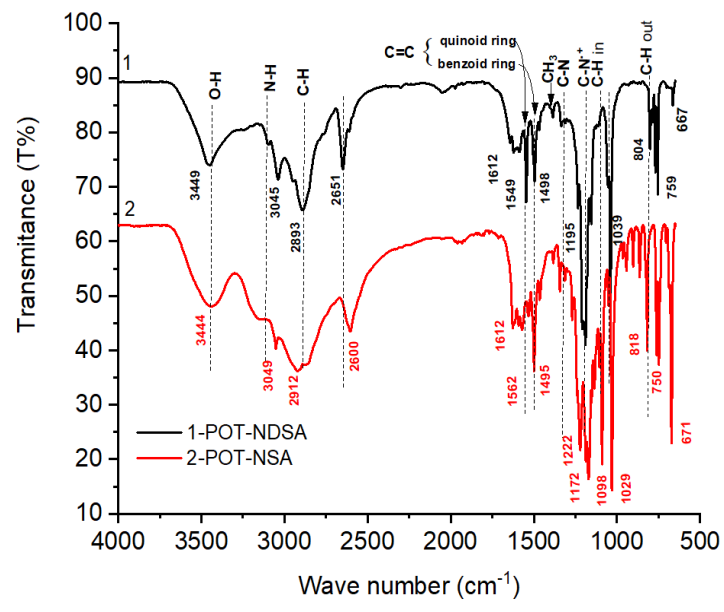


c)

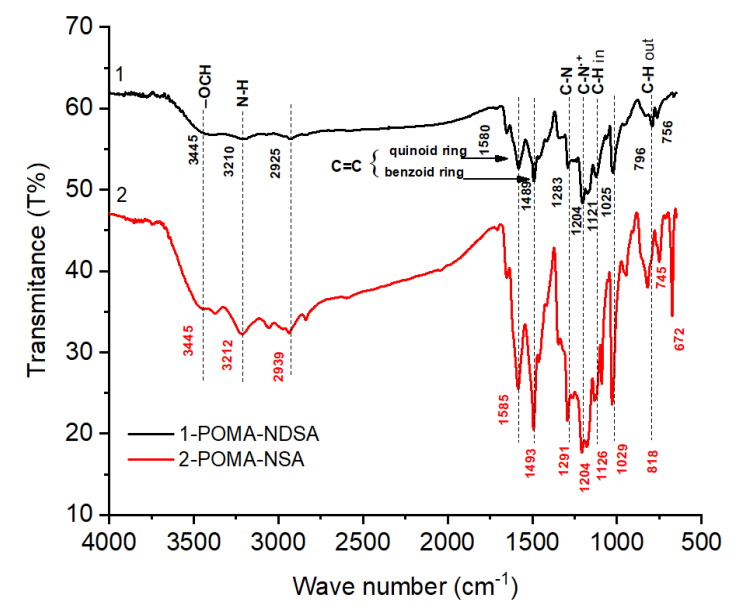

Fig. 2 FTIR spectra of polymers doped with NDSA and NSA chemically synthesised with $\left(\mathrm{NH}_{4}\right)_{2} \mathrm{~S}_{2} \mathrm{O}_{8}$ as polymerisation initiator: a) PANI-NDSA (black line) and PANI-NSA (red line); b) POT-NDSA (black line) and POT-NSA (red line); c) POMA- NDSA (black line) and POMA-NSA (red line).

The FT-IR spectra of poly(o-methoxyaniline) samples doped with NDSA and NSA in Fig. 2c showed similar peaks for both compounds with associated small shifts in their locations. The intensities of the bands in these samples are lower as compared to those found in the poly(o-toluidine) samples. The $\mathrm{N}-\mathrm{H}$ stretching bond appeared at 3210-3212 $\mathrm{cm}^{-1}$ as a small band. It is interesting to note from Fig. $2 \mathbf{c}$ that the intensity of the N-H peak is smaller than that observed in poly(o-toluidine) doped with NDSA/NSA. This is because of the type of polymer used, which has an $\mathrm{OCH}_{3}$ group that can impede the growth reaction, and which seems to be associated with the N-H stretching vibration. A small band at $2925-2939 \mathrm{~cm}^{-1}$ can be assigned to a C-H stretching bond associated with the NDSA and NSA dopants in POMA-NDSA/NSA. The peaks at 1588 and $1489 \mathrm{~cm}^{-1}$ correspond to quinoid $(\mathrm{C}=\mathrm{C})$ and benzoid vibrations, respectively. The bands at $1283 \mathrm{~cm}^{-1}$ and $1204 \mathrm{~cm}^{-1}$ are due to $\mathrm{C}-\mathrm{N}$ and $\mathrm{C}-\mathrm{N}^{++}$stretching, respectively. The C-H out-of-plane (o/p bending) vibration appeared at $1174 \mathrm{~cm}^{-1}$. There are two bands at $1121 \mathrm{~cm}^{-1}$ and 1025 $\mathrm{cm}^{-1}$ that could be attributed to the alkyl-O group in POMA. The medium-intensity band at $1121 \mathrm{~cm}^{-1}$ suggests polaron bonding, whereas the small band at $791 \mathrm{~cm}^{-1}$ is related the 1,2 di-substituted terminal rings' $\mathrm{o} / \mathrm{p}$ bending vibration. A weak band at $1655 \mathrm{~cm}^{-1}$ was noted in POMA-NDSA and POMA-NSA that could be due to $\mathrm{OCH}_{3}$, due to its partial oxidation in the electrolyte during preparation. The peaks mentioned above are in agreement with those previously reported in the literature (Christinelli et al. 2017; Mettai et al. 2018; Zhang et al. 2005).

\section{Conductivity Measurements}

The measurement of the conductivities of polymers doped with NDSA and NSA dopant ions was one of the main purposes of this study, and which depend on the type of polymer and dopant used. Table 1 shows the conductivities of polymers doped with NDSA and NSA by chemical and electrochemical methods. In the instance of 
electrochemically prepared polymer films, the polymer was deposited on the special Pt working electrode (diameter $1 \mathrm{~cm})$. The counter electrode was a Ti mesh $(30 \mathrm{~mm} \times 40 \mathrm{~mm})$ coated with iridium oxide. The polymer powder was collected from the surface of the electrode which, after drying, was used for numerous experiments and pressed into IR discs.

It is clear from Table 1 that the conductivities of polymers prepared by electrochemical polymerisation are greater than for their analogues prepared by the chemical method due to small fibrous chains in the uniform arrangement of the monomer structures which have an effect on the number of charge carriers and thus affect the conductivity (Delvaux et al. 2000; Li et al. 2011). The highest conductivity $\left(0.65 / 0.98 \mathrm{~S} \mathrm{~cm}^{-1}\right)$ was obtained for PANI doped with NDSA, while the conductivities of POT-NDSA and POMA-NDSA were found to be $8.87 \times 10^{-6} \mathrm{~S} \mathrm{~cm}^{-1}$ and $5.21 \times$ $10^{-4} \mathrm{~S} \mathrm{~cm}^{-1}$, respectively. Generally, the conductivities of the PANI films in this work were less than PANI products that had been doped with inorganic acid $\left(\mathrm{HCl}, \mathrm{H}_{2} \mathrm{SO}_{4}\right.$ ) (Cao et al. 1989; Catedral et al. 2004). This is related to of the kind of dopant ions used in the polymerisation process, which have large molecular sizes compared to $\mathrm{HCl}$ or $\mathrm{H}_{2} \mathrm{SO}_{4}$ used in the previous work. The proton released from the dopant acid is considered to be of particular importance due to the fact that this proton has a significant influence on the level of protonation. NDSA and NSA dopant ions need a longer time to release protons compared to $\mathrm{HCl}$ or $\mathrm{H}_{2} \mathrm{SO}_{4}$ dopants, which is one of the reasons for the low conductivities of these polymers.

Table 1. Conductivities of polymers doped with NDSA and NSA at room temperature $\left(25 \pm 2^{\circ} \mathrm{C}\right)$

\begin{tabular}{cccc}
\hline Polymers & Dopant ion & $\begin{array}{c}\sigma_{\mathrm{RT}}\left(\mathrm{S} \mathrm{cm}^{-1}\right) \text { measurement } \\
\text { chemical method }\end{array}$ & $\begin{array}{c}\sigma_{\mathrm{RT}}\left(\mathrm{S} \mathrm{cm}^{-1}\right) \text { measurement } \\
\text { electrochemical method }\end{array}$ \\
\hline Polyaniline & NDSA & $6.50 \times 10^{-1}$ & $9.82 \times 10^{-1}$ \\
Polytoluidine & NDSA & $8.87 \times 10^{-6}$ & $1.21 \times 10^{-4}$ \\
Polyanisidine & NDSA & $5.21 \times 10^{-4}$ & $5.86 \times 10^{-3}$ \\
Polyaniline & NAS & $3.30 \times 10^{-2}$ & $1.2 \times 10^{-1}$ \\
Polytoluidine & NAS & $2.78 \times 10^{-6}$ & $6.83 \times 10^{-5}$ \\
Polyanisidine & NAS & $1.30 \times 10^{-5}$ & $5.13 \times 10^{-4}$ \\
\hline
\end{tabular}

In this work, the conductivities of both poly (o-toluidine)-NDSA and poly(o-methoxyaniline)-NDSA were less than the conductivity of polyaniline-NDSA; this may be because of the methoxy $\left(-\mathrm{OCH}_{3}\right)$ and $-\mathrm{CH}_{3}$ groups located at the ortho site of the aromatic ring structure of the monomers. These groups cause significant steric effects which can impede the polymerisation. This can lead to a decrease in the conductivity of such products compared to PANI (which does not have an alkyl-substituted group). Another possible reason for their low conductivity is the structure of the monomer used in the synthesis of the polymer (Cao et al. 1989). The structures of the monomers and dopant ions used are illustrated in Fig. 1. It is clear from Table 1 that the conductivities of POMA doped with NDSA or NSA are greater than that of POT doped with the same ions. This can be attributed to electronic effects (inductive 
effect and conjugative effect), and steric effects due to- $\mathrm{OCH}_{3}$ and- $\mathrm{CH}_{3}$. It is well known that the electronic effect of the methyl group is weak; however, its steric effect is stronger than that of the methoxy group due to the ease of rotation of the $\mathrm{O}-\mathrm{C}$ bond in methoxy which reduces the steric effect. Therefore, the strong steric hindrance of $\mathrm{CH}_{3}$ in POT results in more product crosslinking, shorter chains and lower doping levels compared to POMA. Previous studies have confirmed that the conductivity of the polymer is decreased with decreasing length of chain due to the reduction in electron movement along the chain (Jamal et al. 2008). The effects described could be the reasons why POT shows a lower conductivity than POMA when they are doped with identical dopant ions.

In the case of the conductivities of polymers doped with NSA, the conductivity of PANI-NSA was $0.033 \mathrm{~S} . c m^{-1}$ while the conductivities of POT-NSA and POMA-NSA were $2.78 \times 10^{-6} \mathrm{~S} \mathrm{~cm}^{-1}$ and $1.3 \times 10^{-5} \mathrm{~S} \mathrm{~cm}^{-1}$, respectively. Accordingly, we can see that conductivities of the products of PANI, POT and POMA doped with NSA are less than those of the same products when doped with NDSA, despite the size of the NSA dopant ion being smaller than that of NDSA. This is because the NSA dopant reacts weakly with the monomers during polymerisation, and needs a longer period to release protons. Therefore, this could be a reason for the decreased effectiveness of the electron transfer process in the POT film.

\section{Thermogravimetric Analysis}

Thermogravimetric analysis (TGA) monitors the change in weight of a polymer as function of temperature change. This is included in the investigation of the polymer decomposition and to determine the amount of water loss as well as other volatile substances (Aphesteguy and Jacobo 2007). In this work, the TGA technique is used to identify the thermal stabilities of the polymer samples synthesised from different monomers and organic dopant ions. Polyaniline, poly(o-methoxyaniline) and poly(o-toluidine) were synthesised using chemical polymerisation in this study. Fig. 3 shows TGA thermograms of polyaniline, poly(o-toluidine) and poly(o-methoxyaniline) doped individually with NDSA and NSA. Three weight loss steps were observed in the PANI-NDSA thermogram. The first step was due to organic solvent loss, which started at $52^{\circ} \mathrm{C}$ (an organic solvent, acetone, was used to rinse the polymers, whereas the second step is attributed to dopant ion evaporation at $188^{\circ} \mathrm{C}$. The last step, which occurred at $366^{\circ} \mathrm{C}$, is associated with the degradation of the polymer itself. The weight loss steps for PANI-NSA were found to occur at $90{ }^{\circ} \mathrm{C}, 243{ }^{\circ} \mathrm{C}$ and $452{ }^{\circ} \mathrm{C}$ due to the removal of moisture, dopant anion evaporation, and degradation of PANI-NSA, respectively. POT products also showed three weight loss stages as a function of temperature, as described in Table 2.

However, the TGA thermograms of poly(o-methoxyaniline) in Fig. 2 showed just two stages of weight loss. The first stage of weight loss appeared at $122^{\circ} \mathrm{C}$, which is caused by the removal of the dopant (NDSA/NSA). The second stage is related to the polymer degradation, which occurs at $323.97{ }^{\circ} \mathrm{C}$. It is noted that the absence of water in these polymers could be because the polymer was dried at $50{ }^{\circ} \mathrm{C}$ in the oven; further details about the degree of weight loss for polymers are shown in Table 2. 


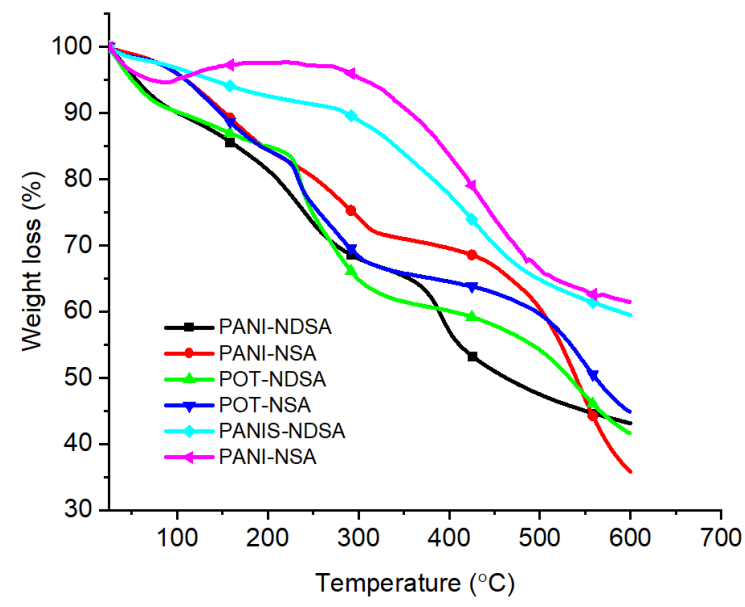

Fig. 3 TGA thermogram of polymers doped with NDSA and NSA chemically synthesised with $\left(\mathrm{NH}_{4}\right)_{2} \mathrm{~S}_{2} \mathrm{O}_{8}$ as the polymerisation initiator.

Table 2 Stages of weight loss for the polymers

\begin{tabular}{lccc}
\hline $\begin{array}{c}\text { Conducting } \\
\text { polymers }\end{array}$ & $\begin{array}{c}\text { Temperature loss of } \\
\text { water/solvent }\left({ }^{\circ} \mathrm{C}\right)\end{array}$ & $\begin{array}{c}\text { Temperature Loss of } \\
\text { dopant anions }\left({ }^{\circ} \mathrm{C}\right)\end{array}$ & $\begin{array}{c}\text { Temperature Backbone } \\
\text { degradation }\left({ }^{\circ} \mathrm{C}\right)\end{array}$ \\
\hline PANI-NDSA & 52 & 188 & 368 \\
PANI-NSA & 90 & 243 & 452 \\
POT-NDSA & $40-70$ & 225 & 426 \\
POT-NSA & 75 & 220 & 459 \\
PANIS-NDSA & 122 & - & 327 \\
PANIS-NSA & 90 & - & 355 \\
\hline
\end{tabular}

\section{Morphological Characterisation}

Fig. 4 shows the morphologies of polyaniline, poly(o-toluidine) and poly(o-methoxyaniline) doped with NDSA/NSA as produced via chemical synthesis (use of $\left(\mathrm{NH}_{4}\right)_{2} \mathrm{~S}_{2} \mathrm{O}_{8}$ oxidising agent). From Fig. 4a, it is clear that the morphology of PANI-NDSA has two irregular-shaped regions consisting of fibrous particles and small agglomerated particles, while the morphology of POMA-NDSA (Fig. 4c) shows a larger aggregation of particles than that obtained in PANI films, producing a large lumpy morphology. The morphology of POT-NDSA and POTNSA, as illustrated in Fig. 4b and e, respectively, resemble large plates but are uniform structures with no noticeable changes of shape observed between them. However, the surface morphologies of PANI and POMA are completely changed when doped with NSA, as shown in Fig. 4d, and f, respectively. This confirmed that the doping agents are of great significance with regard to modification of the morphology in terms of the resultant surface and size of composites (Alesary et al. 2018). We can see that the morphology of PANI-NSA, unlike that seen for PANI-NDSA, 
consists of one region of agglomerated particles, while there are two regions in the morphology of POMA doped with NSA, the first region being agglomerated with very small amorphous particles whilst the second does not have a clear surface and is coarse. It can be concluded that changing the monomer and dopant ion have an important influence on the morphology of the resultant polymer salts (Alesary et al. 2018; Yalcinkaya et al. 2010).
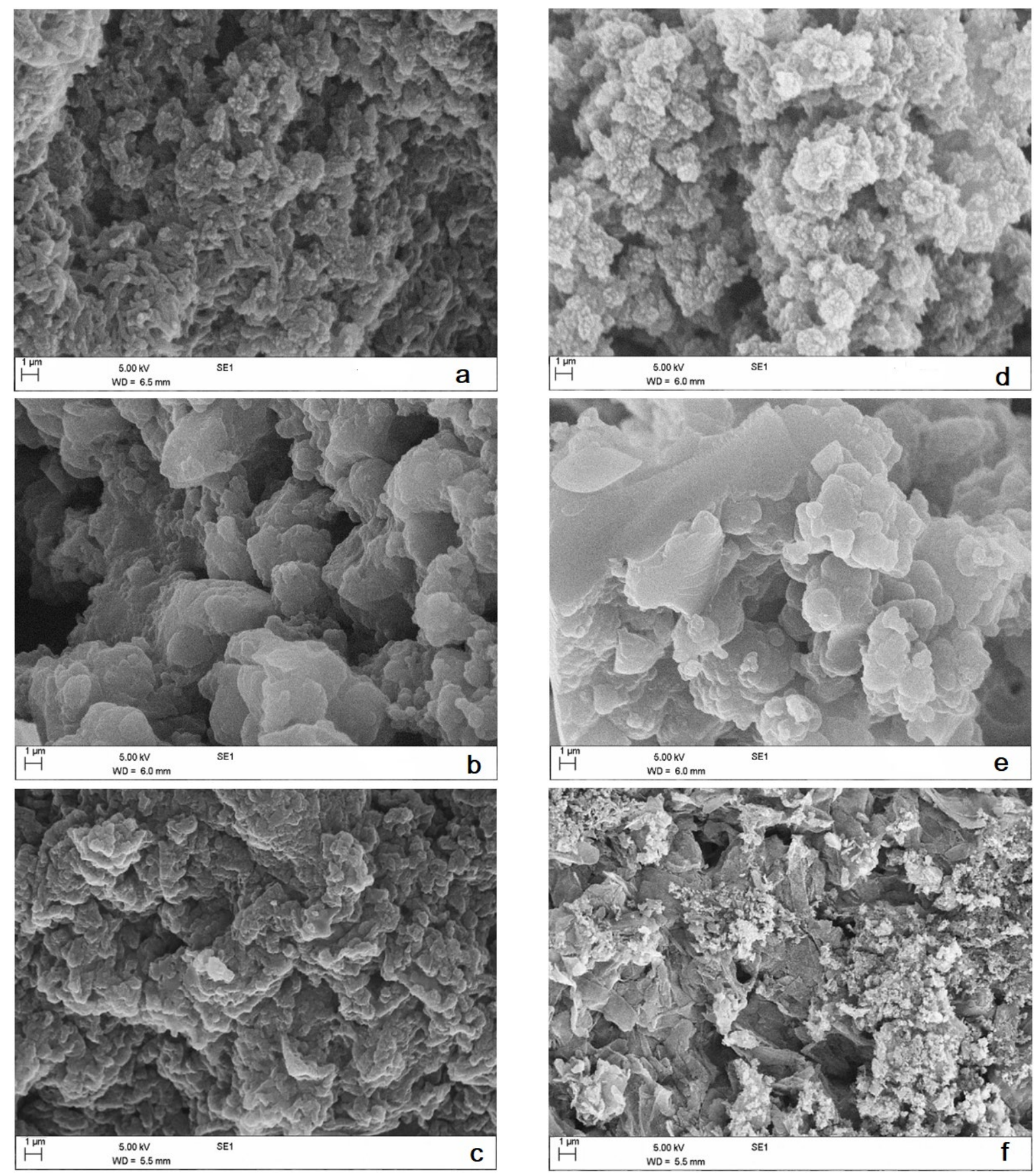

Fig. 4 SEM photographs for polymers produced by chemical polymerisation under the conditions described in the experimental section; (a) PANI-NDSA, (b) POT-NDSA, (c) POMA-NDSA, (d) PANI-NSA, (e) POT-NSA and (f) POMA-NSA 
The morphologies of all polymer salts show obvious changes due to the use of electrochemical polymerisation, as shown in Fig. 5. In this method, the shape of PANI-NDSA resembles lines or homogenous chains and it seems that PANI-NDSA has a large porous surface compared to that seen for PANI-NSA. This could explain why the conductivity of PANI with NDSA/NSA dopant ions as synthesised by electrochemical polymerisation is greater than that of polyaniline produced by chemical polymerisation with dopant organic ions (NDSA and NSA), as shown in Table 1. The morphology of POT-NDSA (Fig. 5b) shows a uniform morphology having smaller, more globular plates than POT-NSA (Fig. 5e). The size of the particles in both is much smaller than was observed for POTNDSA/NSA polymerised by the chemical method. The surface morphology of the POMA electrochemically produced with an NDSA dopant contained two regions which resemble chains agglomerated together and a lumpy structure, while POMA-NSA (Fig. 5f) shows a coarser surface than in POMA-NDSA and a different shape to the analogous polymer in Fig. 4f. The results of this study (Figs. 4 and 5) confirm the presence of a significant difference in morphology of these polymers depending on the monomer, dopant ions and method of polymerisation used.
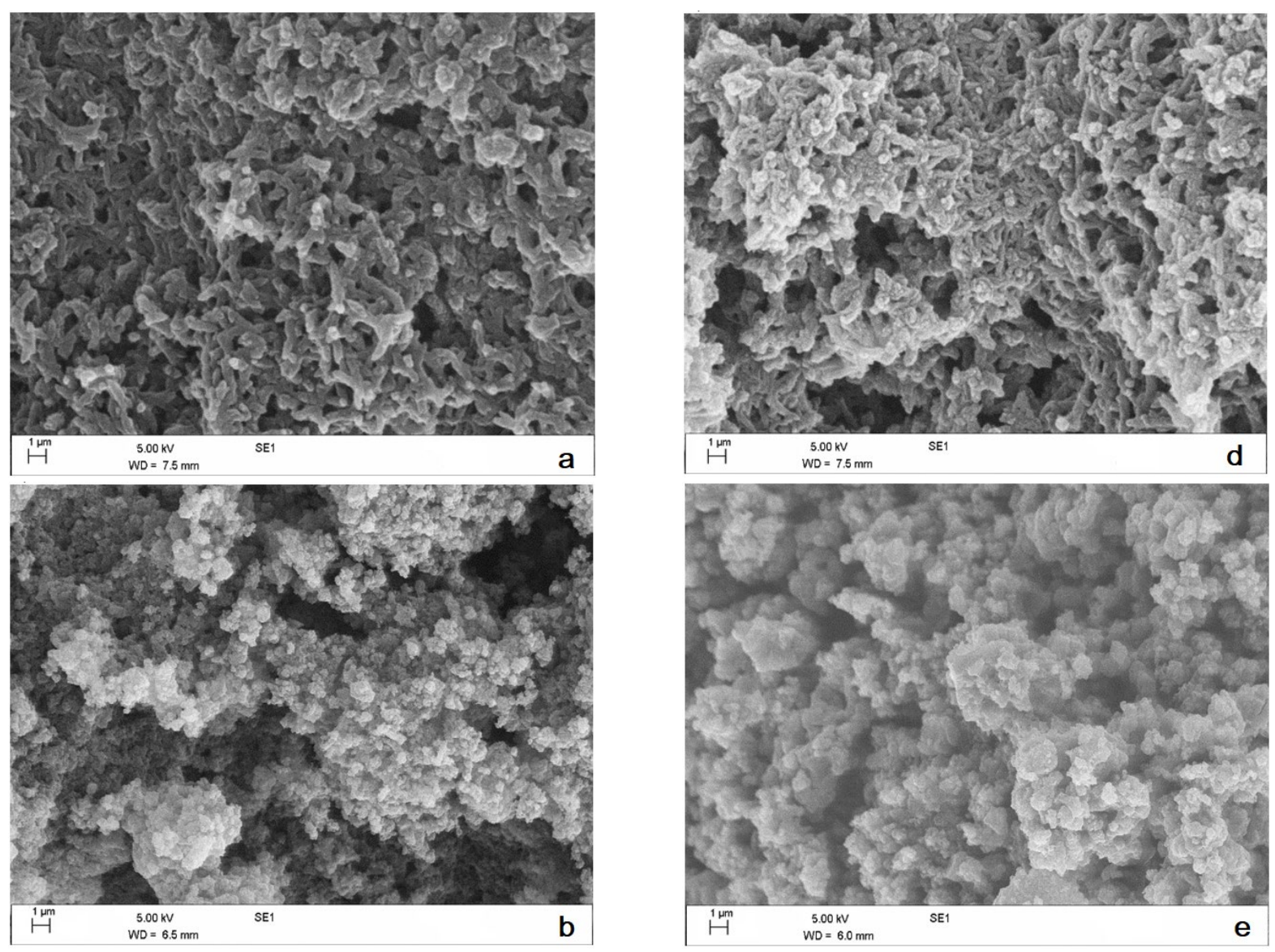

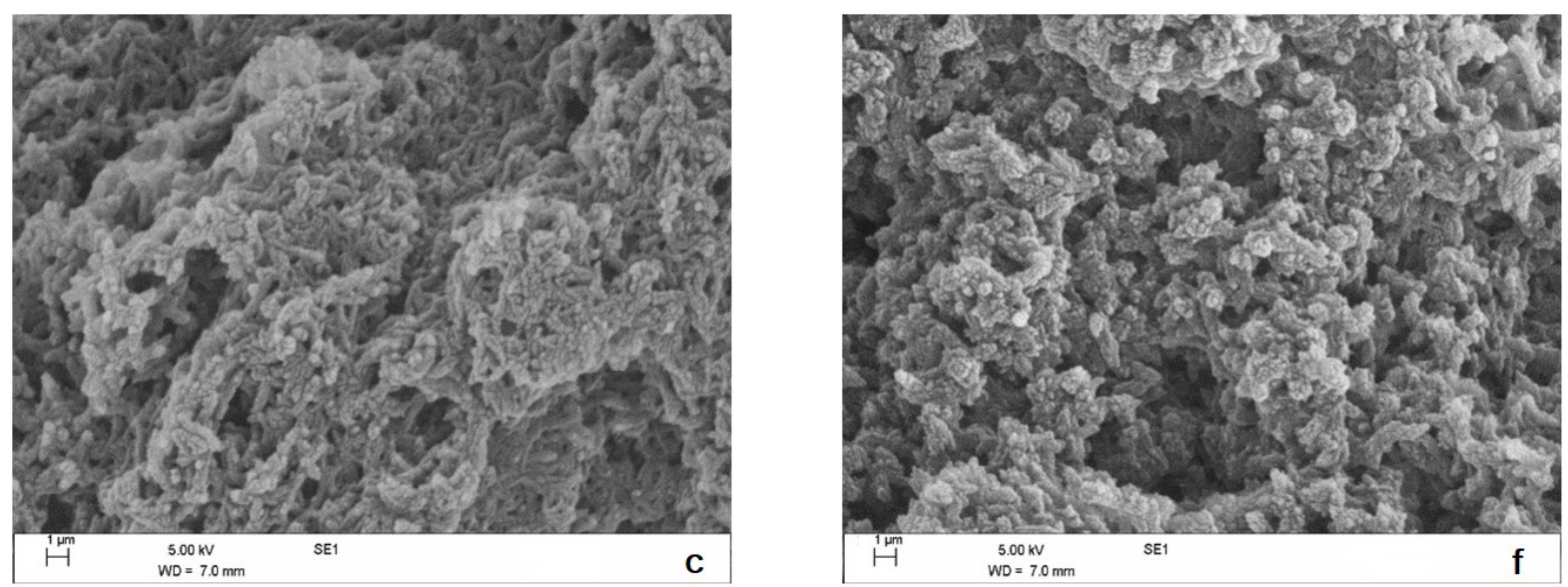

Fig. 5 SEM photographs for polymers produced by electrochemical polymerisation under the conditions described in Fig. 6; (a) PANI-NDSA, (b) POT-NDSA, (c) POMA-NDSA, (d) PANI-NSA, (e) POT-NSA and (f) POMA-NSA

\section{Cyclic voltammetry studies}

\section{Electropolymerisation of monomers}

The electropolymerisation of different conjugate monomers were carried out on the Pt working electrode (1 mm dia.) in $1 \mathrm{M}$ organic acid dopant (NDSA and NSA separately) solutions containing $0.2 \mathrm{M}$ aniline, o-toluidine, and omethoxyaniline separately at a scan rate $20 \mathrm{mV} \mathrm{s}^{-1}$ for 10 cycles using cyclic voltammetry (CV); the potential range used for PANI and POT films doped with NDSA/NSA was between -0.2 and $1.1 \mathrm{~V}$, while that for POMANDSA/NSA films was between -0.2 and $1.2 \mathrm{~V}$. All experiments were performed at room temperature $\left(25 \pm 2{ }^{\circ} \mathrm{C}\right.$. The potential range used for PANI and POT films was -0.2 to $1.1 \mathrm{~V}$, while for the POMA film was -0.2 to $1.2 \mathrm{~V}$. The reason for this is that the potential window for any conducting polymer varies depending on the structure of the deposited polymer. Further, it is related to the potentials at which nucleation and the oxidation of the monomer occur, the bounds of which define what is referred to as a nucleation loop. For PANI and POT films, the nucleation loop in the first cycle was at 1.0 V while for POMA was at 1.09 V, as shown in Fig. 6. POMA does not grow when the positive potential is less than $1.1 \mathrm{~V}$ under such conditions, and for this reason the potential range used for POMA was -0.2 to $1.2 \mathrm{~V}$, in contrast to the PANI and POT films (-0.2 to $1.1 \mathrm{~V})$. The nucleation loop vanished in the following cycles because of the persistent growth of the film preventing further nucleation in subsequent scans. 


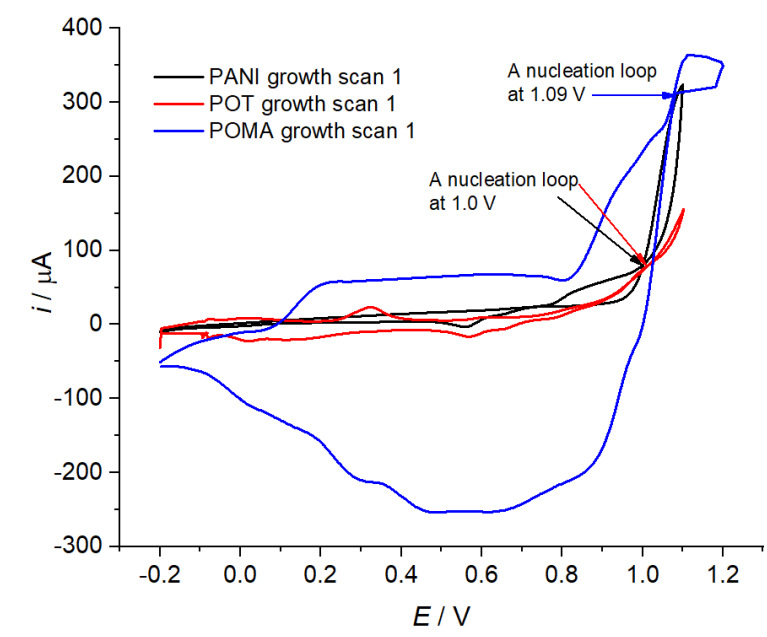

Fig. 6 The nucleation loop for the PANI, POT, and POMA films for scan 1 of each of the polymers deposited in Fig. 7.

In all experiments, the growth of polymer films starts to develop significantly, resulting in an increase in the current peaks with an increasing number of cycles, as shown in Fig. 7. This implies that the charge and amount of polymer on the working electrode are increased with increasing cycle number (Nie et al. 2008). The results show that the electroactive behaviour of the PANI films doped with NDSA/NSA is greater than that for POT and POMA salts using the same dopants, while lower current peaks were observed for POT films compared with other polymers. This may be due to the strong steric effect and reduced electronic transfer that occurs because of the alkyl group on the ortho site of the benzene ring of the monomer (toluidine), reducing the strength of the bonds between chains of poly(o-toluidine) compared to the polyaniline (Leclerc et al. 1993; Mello et al. 1995). It may be noted from the results that the rate of growth for NDSA dopant ions is greater than that for NSA under the same conditions (i.e. in the presence of the same monomer). This suggests that the NDSA dopant ion tends to interact more strongly with the ion pairs of the anilinium radical cation (polaron) on the film chains compared to NSA.

Two main redox couples are observed in the CVs of PANI-NDSA/NSA, while more than four redox couples can be observed in the POT-NDSA/NSA and POMA-NDSA/NSA. In the PANI films, the first oxidation process (at $c a$. $0.33 \mathrm{~V}$ ) correspond to the leucoemeraldine base (fully reduced form) that converts to the protonated emeraldine (half oxidised form) while the second redox peaks (at $c a .0 .94 \mathrm{~V}$ ) are related to the protonated emeraldine converting to the fully oxidized form (pernigraniline structure), and the opposite for the reduction processes. The redox peaks in the intermediate region between $0.30-0.40 \mathrm{~V}$ may be associated with the crosslinked PANI salts, These results are analogous to those reported in the literature (Borole et al. 2004). In the cases of POMA and POT, there are three intermediate redox peaks, possibly indicating that the potential of redox peaks of the monomers is related to the type and size of the anion present and the increase in the number of redox peaks is strongly influenced by the size and nature of the species present in the electrolytic bath. It was observed that both the anodic and cathodic current peaks 
associated with the polymerization of anisidine and o-toluidine films are greatly influenced by the presence of organic sulphonic acids in the electrolytic bath.

The potential locations of the redox couples for POT-NDSA/NSA and POMA-NDSA/NSA polymers were significantly different to those of PANI-NDSA/NSA, as shown in Fig. 7a and $\mathbf{d}$. The increased number of potential peaks in the POT and POMA salts compared with PANI suggested that the electronic effect of the methyl substituent in POT and the methoxy substituent in POMA increased the extent of the crosslinking present. This could lead to a decrease in the doping levels and increase in the ratio of quinoid to benzenoid ring modes of POTs and POMA salts, producing a polymer with a low electrical conductivity, as reported in Table $\mathbf{1}$ where the quinoid ring in the PANI structure is more electron-withdrawing than the benzene ring, resulting in a reduction in the associated electrical conductivity (Abdiryim et al. 2005; Jamal et al. 2008). It is worth noting that the stability and reversibility of the PANI films and other films decreased in the electrolytes (monomer-free) with increasing thickness, i.e., with increasing scan number. Therefore, we deposited a thin layer of films in this study because the increased thickness of the deposited polymer is not electrochemically stable due to the reduced porosity of the polymer, which led to hindrance of the movement of cations and/or anions through the polymer network as described in our previous work (Ismail et al. 2019a).

a)

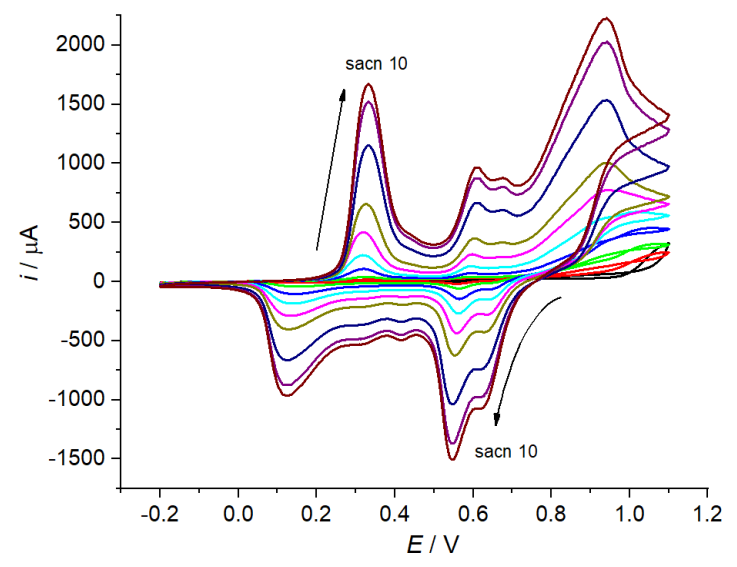

b)

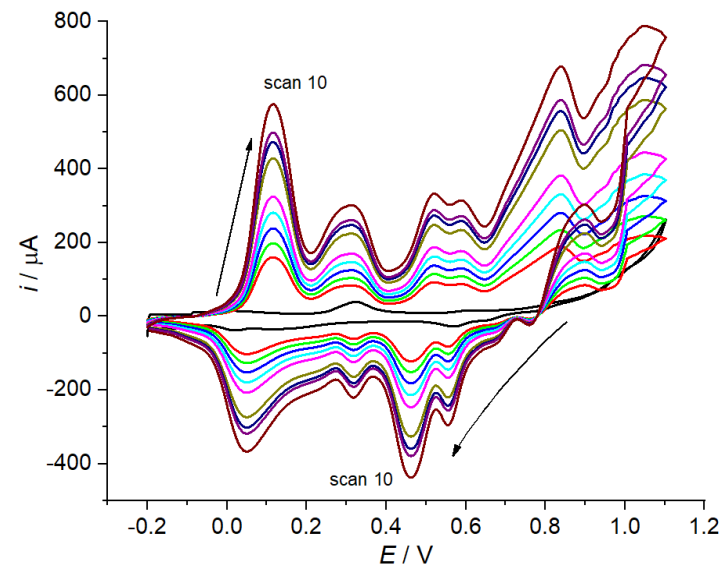

d)

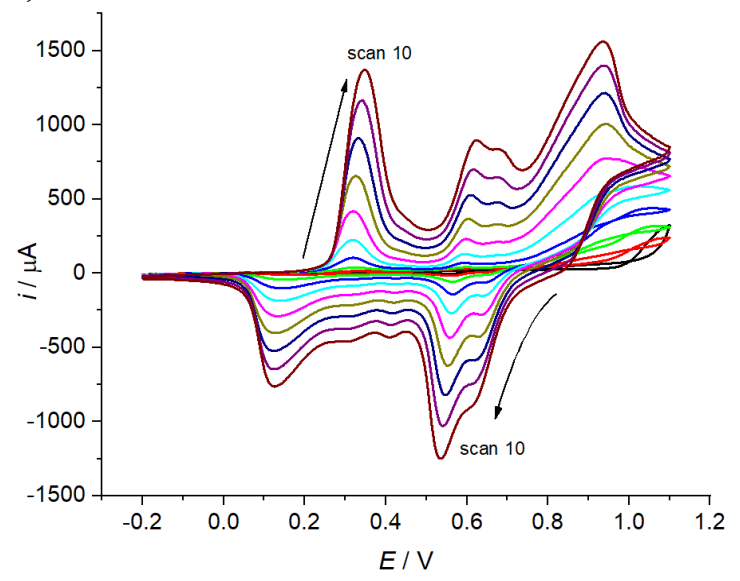

e)

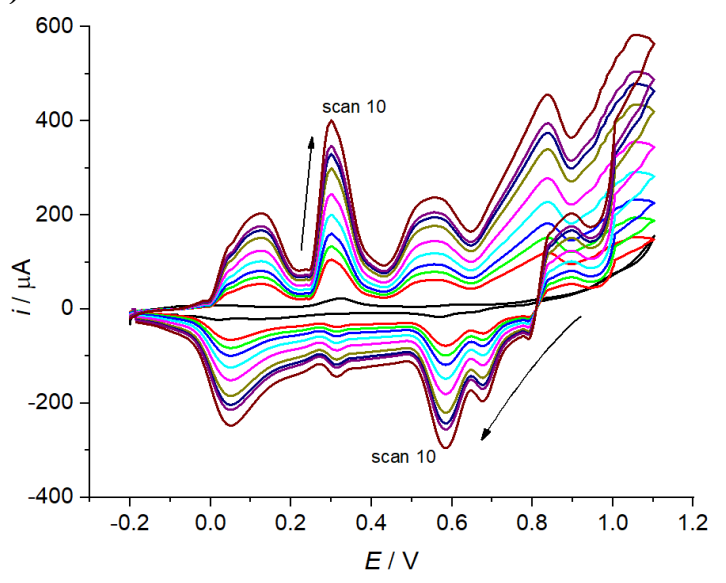


c)

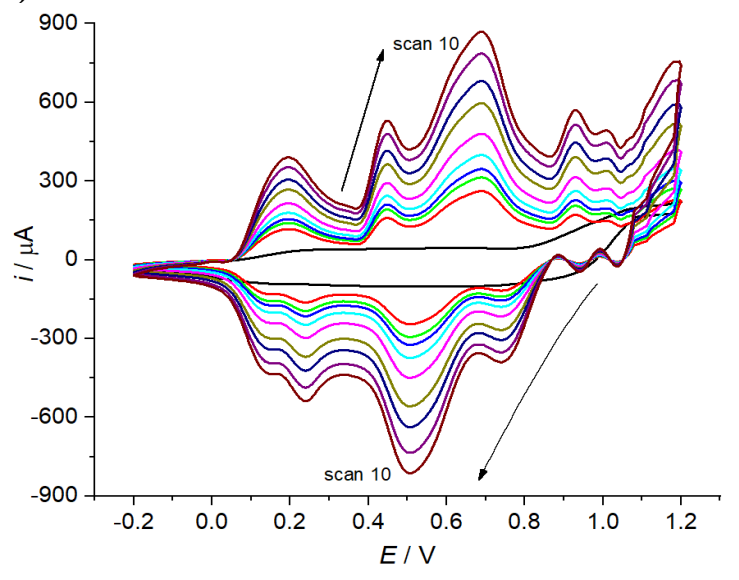

f)

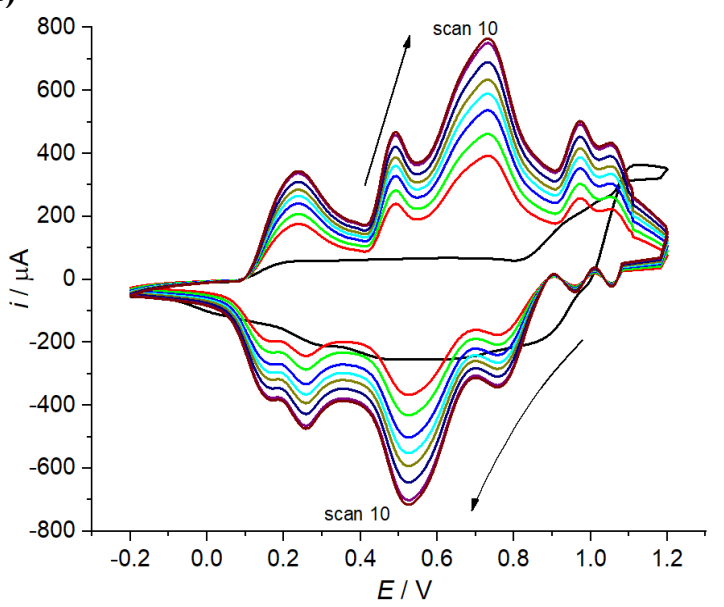

Fig. 7 The CV curves recorded during the electropolymerisation of the polymer films in $0.2 \mathrm{M}$ monomer and 1.0 $\mathrm{M}$ organic acid (NDSA and NSA) for a potential window between -0.2 and 1.1/1.2 $\mathrm{V}$ at scan rate of 20 $\mathrm{mVs}^{-1}$ for 10 cycles; (a) PANI-NDSA, (b) POT-NDSA, (c) POMA-NDSA, (d) PANI-NSA, (e) POT-NSA and (f) POMA-NSA.

The thicknesses $(d)$ of all deposited polymers are reported in Table 3 and were estimated according to equation (2), whereas the charge $(Q)$ in the coulomb (C) under the more cathodic peaks can be calculated from the integral of the cathodic current with time for the last scan of the deposited film. The thickness of the polymer can be measured based on the charge passed at the previous scan number.

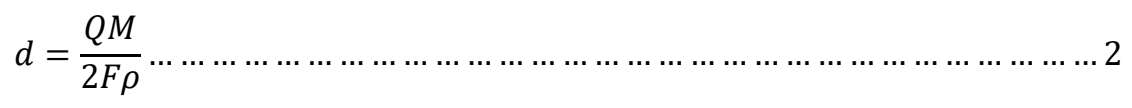

where $Q$ is the value of overall charge for the electrodeposition polymer (see Table 3), $\rho$ is the polymer density, $M$ is the molar mass of the relevant monomer (in $\mathrm{g} / \mathrm{mol}$ ), and $F$ is the Faraday constant $(96,485 \mathrm{C} / \mathrm{mol}$ ) (Ren et al. 2011; Shinde and Patil 2013). It is interesting to observe that the thickness of the polymers increases with the increase in the deposited charge, as shown in the Table 3.

From the results above, we can conclude that there are two important factors that can affect polymerisation rate, thickness, and other properties of the polymer. Firstly, the greatest polymerisation rate was found in NDSA compared to NSA under the appropriate conditions for the monomer used, strongly indicating it is affected by the nature of the dopant anion present in the electrolyte. Secondly, polymerisation rate can also be attributed to the type of monomer, where polymers formed from aniline in the presence of different dopant ions (NDSA or NSA) can have faster growth rates compared to the other polymers used in this study due to the absence of any steric effect from the methyl and methoxy groups. 
Table 3 Charge values and the thickness of polymer films deposited from different organic acidic electrolytes under otherwise identical conditions, as per Figure 7.

\begin{tabular}{cccc}
\hline Samples & $\begin{array}{c}Q / \text { C measured from } \\
\text { cathodic current } 10^{\text {th }} \text { cycle }\end{array}$ & $\begin{array}{c}\text { Density of polymer } \\
\mathrm{g} \mathrm{cm}^{-1}\end{array}$ & $\begin{array}{c}\text { Thickness of } \\
\text { polymer }(\mathrm{nm})\end{array}$ \\
\hline PANI-NDSA & 0.02439 & 1.33 & 88.5 \\
PANI-NSA & 0.0208 & & 75.5 \\
POT-NDSA & 0.00995 & 1.34 & 41.2 \\
POT-NSA & 0.00739 & $($ Shinde and Patil 2013) & 30.6 \\
POMA-NDSA & 0.02102 & 1.50 & 89.4 \\
POMA-NSA & 0.01853 & $(\underline{\text { Ren et al. 2011) }})$ & 78.8 \\
\hline
\end{tabular}

\section{Electrochemical response of polymers}

After electrodeposition of the polymer film via cyclic voltammetry (Fig. 7), the redox behaviour and stability of the PANI, POT and POMA salts were investigated in similar background solutions (monomer-free) using cyclic voltammetry, as shown in Fig. 8. The concentration of the background solution was 0.5 M NDSA/NSA and the scan rate was $20 \mathrm{mV} \mathrm{s}^{-1}$ in all experiments. The potential window used for PANI and POT films was between -2.0 and $1.1 \mathrm{~V}$ while for POMA films was between -0.2 and $1.2 \mathrm{~V}$, depending on the potential window of the deposited polymer. The current peaks of the films immersed in $0.5 \mathrm{M}$ original organic acid electrolytes were close to the current peaks of the original films that were grown. As shown in Fig. 8a and d, two separate redox peaks can be observed in the electrochemical responses of the PANI films, and these are identical to the CV peak shape of PANI. This implies that electrochemical activity of PANI film is analogous to that of its parent PANI in both acid solutions (NDSA and NSA). The same, with regard to redox activity, was observed for the other polymers. In addition, the stabilities of all the polymers doped with the NDSA electrolyte was greater than those of the polymers doped with the NSA electrolyte. This is possibly due to polymer growth from NDSA being more conductive and the morphologies more porous than those observed with NSA.

It was found that the highest electrochemical stability corresponding to the redox peaks was observed for the POMA-NDSA film (60.30\% charge redox retention) as exposed to 0.5 M NDSA, compared to the other polymers. On the other hand, the worst electrochemical stability was observed for the POT-NSA $(30.41 \%$ charge redox retention) followed by POT-NDSA (43.31\% charge redox retention) cycled in $0.5 \mathrm{M}$ NSA and NDSA solutions, respectively. Herein, we observed a decrease in the peak currents as a function of increasing scan number; thus, there is a shift in the peak potentials and associated CV shapes were changed. This could be attributed to degradation of the film when switching to the overoxidation potential, which led to poor stability during redox cycling, as reported in previous studies (Bauermann and Bartlett 2005; Mažeikien and Malinauskas 2002). 
These results showed that the electrochemical stability of the polymer films in the electrolyte depends strongly on the type of polymer and also the nature of the anion present in solution. According to our experimental results, as reported in Table 4, the electrochemical stability of polymers prepared from different monomers and organic acidic dopants take the following order: POMA-NDSA > PANI- NDSA $>$ POMA-NSA $>$ PANI-NSA $>$ POT-NDSA $>$ POT-NSA.

a)

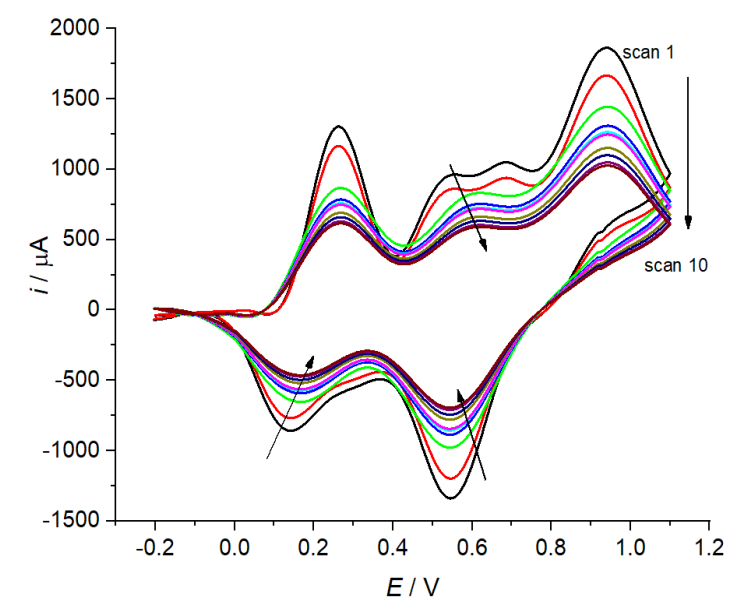

b)

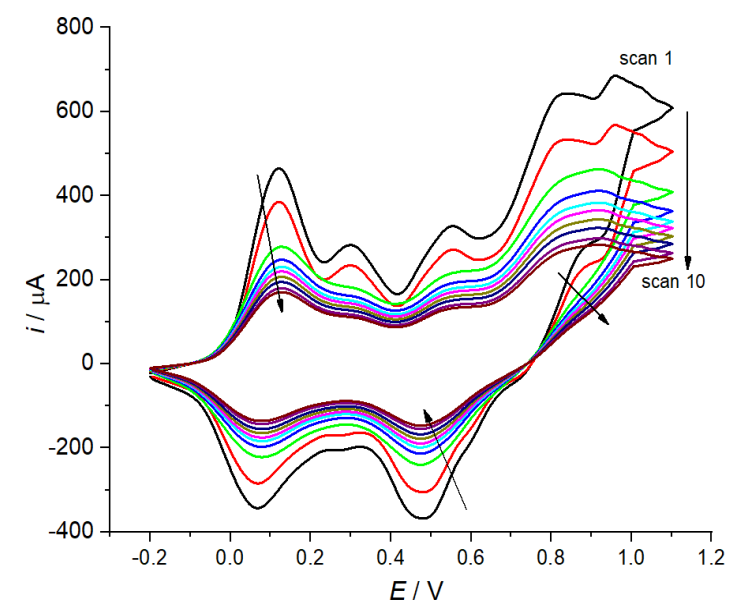

c) d)

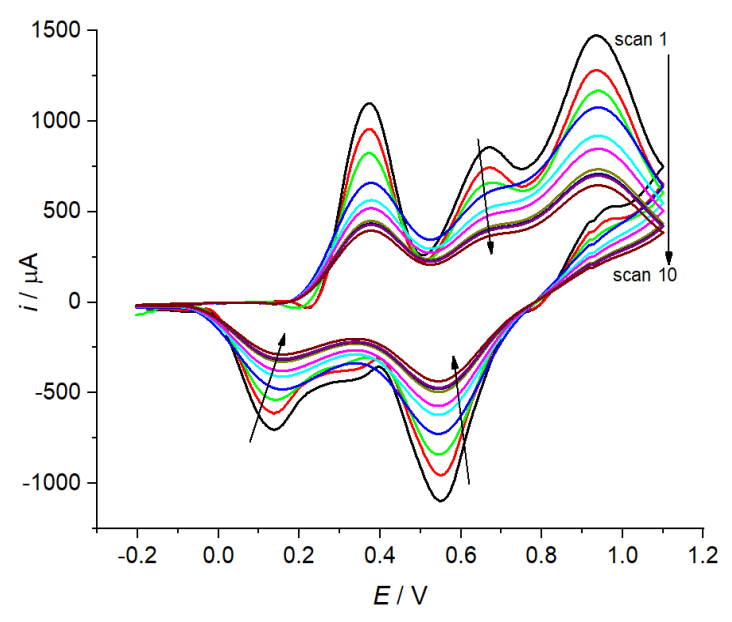

e)

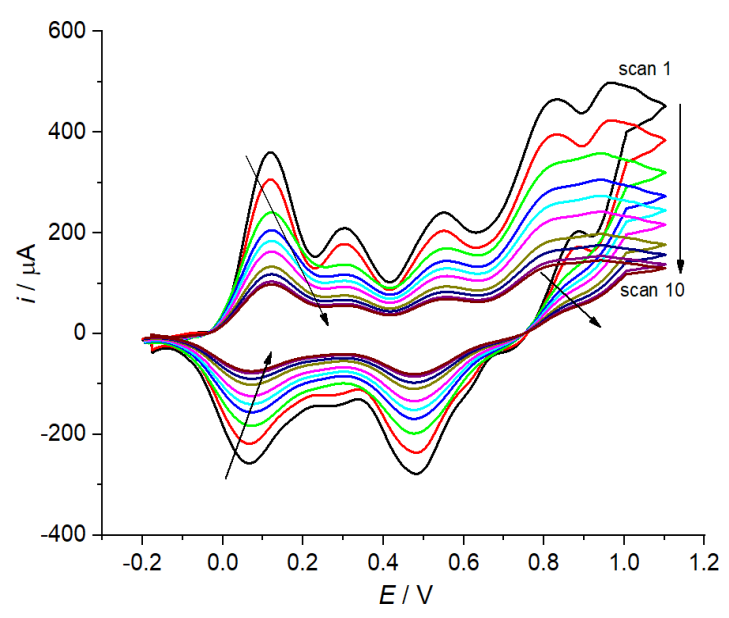

f) 

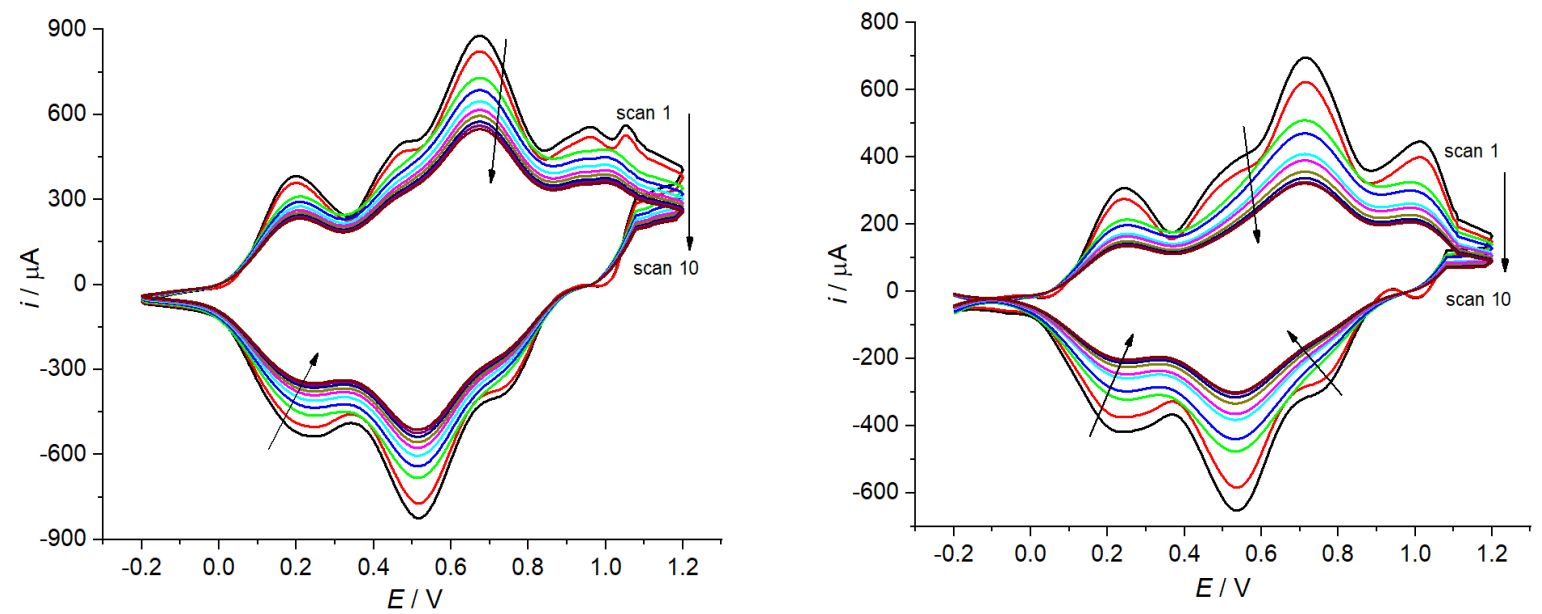

Fig. 8 Voltammetric responses for films (Figure 7); (a) PANI-NDSA, (b) POT-NDSA, (c) POMA-NDSA, (d) PANI-NSA, (e) POT-NSA and (f) POMA-NSA as exposed to $0.5 \mathrm{M}$ of the same background electrolyte (monomer-free), A potential range of $-0.2 \leq \mathrm{E} / \mathrm{V} \leq 1.1 / 1.2$ was applied at $20 \mathrm{mV} \mathrm{s}^{-1}$ for 10 cycles in all cases.

Table 4 Charge values for the electrochemical response for polymer growth in Fig. 7, as cycled in their background electrolytes (monomer-free) at a scan rate of $20 \mathrm{mV} \mathrm{s}^{-1}$, as presented in Fig. 8. The charge was calculated from the CV curves given in Fig. 8 by integration the current of the redox peaks with respect to time. The charges found for cycles 1 and 10 are shown.

\begin{tabular}{ccccc}
\hline Polymer films & $\begin{array}{c}\text { Polymer cycled in } \\
\text { electrolytes }\end{array}$ & $Q /$ C redox $1^{\text {st }}$ cycle & $\begin{array}{c}Q / \text { C redox } 10^{\text {th }} \\
\text { cycle }\end{array}$ & \% Q redox retention \\
\hline PANI- NDSA & 0.5 M NDSA & 0.04342 & 0.02557 & 58.89 \\
PANI- NSA & 0.5 M NSA & 0.03155 & 0.01521 & 48.21 \\
POT- NDSA & 0.5 M NDSA & 0.01741 & 0.00754 & 43.31 \\
POT- NSA & 0.5 M NSA & 0.01233 & 0.00375 & 30.41 \\
POMA- NDSA & 0.5 M NDSA & 0.02552 & 0.01692 & 66.30 \\
POMA- NDSA & 0.5 M NSA & 0.01912 & 0.00961 & 50.26 \\
\hline
\end{tabular}

\section{Conclusion}

In this paper, different conducting polymers have been successfully prepared from raw monomers (aniline, otoluidine and o-methoxyaniline) by chemical and electrochemical polymerisation in the presence of 1,5naphthalenedisulfonic acid (NDSA) and 2-naphthalenesulfoinc acid (NSA) dopant ions. The conductivities of POMA and POT doped with NDSA and NSA were found to be lower than the conductivities of PANI prepared using the same dopant ions. This is because of the type and level of protonation that was used in each case. The molecular sizes of o-toluidine (having a methyl group) and o-methoxyaniline (having a methoxy group) are nominally larger than that of aniline, resulting in a reduction in the growth of long chains of polymer and thus 
decreasing conductivity. The $-\mathrm{OCH}_{3}$ and $-\mathrm{CH}_{3}$ groups have significant steric effects and can reduce to form long chains of polymers and result in a decreased conductivity. It was found that the conductivity of polymers produced by electrochemical methods is greater than the analogous polymers synthesised via chemical polymerisation. The thermal stabilities of POT salts were higher than the PANI and POMA salts, where the degradation of POT salts was found to lie between $425-460^{\circ} \mathrm{C}$, while the degradation of PANI-NDSA and POMA salts was between $325-370$ ${ }^{\circ} \mathrm{C}$. SEM shows a significant difference in the morphology of polymers depending on the monomer, dopant ions, and method of polymerisation used.

The results show a rapid growth rate was observed in PANI films in the electrolytes containing NDSA and NSA under cyclic voltammetric conditions compared to POMA and POT, while it was found that the POMA-NDSA films had the highest electrochemical stability, recording $\sim 66 \%$ retention of redox charge from the initial value. In contrast, POT salts showed lower electrochemical stabilities, recoding $\sim 30 \%$ of retention of redox charge from the initial value. We concluded that the methoxy and methyl groups in PANI derivatives (present at the ortho position in the phenylene ring) play a significant role in determining the physicochemical properties of the synthesised PANI derivatives. As a consequence, the methyl group was found to have a strong steric effect which led to POT salts becoming more oxidised than POMA salts. Thus, the nature of the anion present in the electrolyte and the type of method used strongly affect the subsequent polymerisation of the monomer.

\section{Declaration of Competing Interest}

The authors declare that they have no known competing financial interests or personal relationships that could have appeared to influence the work reported in this paper.

\section{Acknowledgements}

HA wish to acknowledge the financial support of the Ministry of Higher Education and Scientific Research, Iraq, and would also like to thank Prof. Peter Food, for measuring conductivities of samples.

\section{References}

Abdiryim T, Xiao-Gang Z, Jamal R (2005) Synthesis and characterization of poly (o-toluidine) doped with organic sulfonic acid by solid-state polymerization. J Appl Polym Sci 96:1630-1634. https://doi.org/10.1002/app.21614

Alabdullah SS, Ismail HK, Ryder KS, Abbott AP (2020) Evidence supporting an emulsion polymerisation mechanism for the formation of polyaniline. Electrochim Acta 354:136737. https://doi.org/10.1016/j.electacta.2020.136737

Alesary HF, Ismail K, Khudhair AF, Mohammed MQ (2018) Effects of dopant ions on the properties of polyaniline conducting polymer. Orient J Chem 34:2525. http://dx.doi.org/10.13005/ojc/340539 
Aphesteguy JC, Jacobo SE (2007) Synthesis of a soluble polyaniline-ferrite composite: magnetic and electric properties. J Mater Sci 42:7062-7068. https://doi.org/10.1007/s10853-006-1423-7

Banaszczyk J, Schwarz A, De Mey G, Van Langenhove L (2010) The Van der Pauw method for sheet resistance measurements of polypyrrole-coated para-aramide woven fabrics. J Appl Polym Sci117:2553-2558. https://doi.org/10.1002/app.32186

Bauermann L, Bartlett P (2005) EQCM measurements of the ion and solvent flux in thin poly (aniline)-poly (styrenesulfonate) films during redox switching. Electrochim Acta 50:1537-1546. https://doi.org/10.1016/j.electacta.2004.10.011

Bazzaoui EA, Aeiyach S, Lacaze P (1994) Low potential electropolymerization of thiophene in aqueous perchloric acid. J Electroanal Chem 364:63-69. https://doi.org/10.1016/0022-0728(93)02910-A

Borole D, Kapadi U, Kumbhar P, Hundiwale D (2002) Influence of inorganic and organic supporting electrolytes on the electrochemical synthesis of polyaniline, poly (o-toluidine) and their copolymer thin films. Mater Lett 56:685-691. https://doi.org/10.1016/S0167-577X(02)00579-7

Borole D, Kapadi U, Mahulikar P, Hundiwale D (2004) Electrochemical behaviour of polyaniline, poly (o-toluidine) and their copolymer in organic sulphonic acids. Mater Lett 58:3816-3822. https://doi.org/10.1016/j.matlet.2004.07.035

Borole D, Kapadi U, Mahulikar P, Hundiwale D (2006) Electrochemical synthesis and characterization of conducting copolymer: Poly (o-aniline-co-o-toluidine). Mater Lett 60:2447-2452. https://doi.org/10.1016/j.matlet.2006.01.014

Cao Y, Andreatta A, Heeger AJ, Smith P (1989) Influence of chemical polymerization conditions on the properties of polyaniline. Polymer 30:2305-2311. https://doi.org/10.1016/0032-3861(89)90266-8

Catedral M, Tapia A, Sarmago R, Tamayo J, Del Rosario E (2004) Effect of dopant ions on the electrical conductivity and microstructure of polyaniline (emeraldine salt). Science Diliman 16.

Christinelli W, da Trindade L, Trench A, Quintans C, Paranhos C, Pereira E (2017) High-performance energy storage of poly (o-methoxyaniline) film using an ionic liquid as electrolyte. Energy 141:1829-1835. https://doi.org/10.1016/j.energy.2017.11.026

Chujo Y (2011) Conjugated Polymer Synthesis: Methods and Reactions. John Wiley \& Sons.

Delvaux M, Duchet J, Stavaux PY, Legras R, Demoustier-Champagne S (2000) Chemical and electrochemical synthesis of polyaniline micro-and nano-tubules. Synth Met 113:275-280. https://doi.org/10.1016/S0379$\underline{6779(00) 00226-5}$

Deshpande PP, Murali M, Deshpande PP, Galphade VS, More MA (2013) Conducting poly (o-anisidine)-coated steel electrodes for supercapacitors. Chem Pap 67:1066-1071. https://doi.org/10.2478/s11696-013-0317-9

Elmansouri A et al. (2007) Spectroscopic characterization of electrodeposited poly (o-toluidine) thin films and electrical properties of ITO/poly (o-toluidine)/aluminum Schottky diodes. Active and Passive Electronic Components 2007. https://doi.org/10.1155/2007/17846 
Gruia VT, Ispas A, Efimov I, Bund A (2020) Cation exchange behavior during the redox switching of poly (3, 4ethylenedioxythiophene) films. J Solid State Electrochem 24:3231-3244. https://doi.org/10.1007/s10008$\underline{020-04809-6}$

Gustafson MP, Matsumoto K, MacFarlane DR, Winther-Jensen B (2014) An investigation of the properties of conducting polymer alloys for water oxidation. Electrochim Acta 122:166-172. https://doi.org/10.1016/j.electacta.2013.10.022

Hillman AR, Ryder KS, Ismail HK, Unal A, Voorhaar A (2017) Fundamental aspects of electrochemically controlled wetting of nanoscale composite materials. Faraday Discuss 199:75-99. https://doi.org/10.1039/C7FD00060J

Hong X, Liu Y, Li Y, Wang X, Fu J, Wang X (2020) Application progress of polyaniline, polypyrrole and polythiophene in lithium-sulfur batteries. Polymers 12:331. https://doi.org/10.3390/polym12020331

Huang J, Wan M (1999) Polyaniline doped with different sulfonic acids by in situ doping polymerization. J Polym Sci Polym Chem 37:1277-1284. https://doi.org/10.1002/(SICI)1099-0518(19990501)37:9<1277::AIDPOLA7>3.0.CO;2-A

Ismail HK, Alesary HF, Al-Murshedi AY, Kareem JH (2019a) Ion and solvent transfer of polyaniline films electrodeposited from deep eutectic solvents via EQCM. J Solid State Electrochem 23:3107-3121. https://doi.org/10.1007/s10008-019-04415-1

Ismail HK, Alesary HF, Mohammed MQ (2019b) Synthesis and characterisation of polyaniline and/or $\mathrm{MoO}_{2} /$ graphite composites from deep eutectic solvents via chemical polymerisation. J Polym Res 26:65. https://doi.org/10.1007/s10965-019-1732-6

Jamal R, Abdiryim T, Nurulla I (2008) Comparative studies of solid-state synthesized poly (o-methoxyaniline) and poly (o-toluidine). Polym Adv Technol 19:1461-1466. https://doi.org/10.1002/pat.1139

Leclerc M, D'Aprano G, Zotti G (1993) Structure-property relationships in polyaniline derivatives. Synth Met 55:1527-1532. https://doi.org/10.1016/0379-6779(93)90279-6

Li Q, Liu J, Zou J, Chunder A, Chen Y, Zhai L (2011) Synthesis and electrochemical performance of multi-walled carbon nanotube/polyaniline/ $\mathrm{MnO}_{2}$ ternary coaxial nanostructures for supercapacitors. J Power Sources 196:565-572. https://doi.org/10.1016/j.jpowsour.2010.06.073

Mattoso L, Bulhoes L (1992) Synthesis and characterization of poly (o-anisidine) films. Synth Met 52:171-181. https://doi.org/10.1016/0379-6779(92)90305-3

Mažeikien R, Malinauskas A (2002) Electrochemical stability of polyaniline. Eur Polymer J 38:1947-1952. https://doi.org/10.1016/S0014-3057(02)00103-9

Mello SV, Mattoso LHC, Santos Jr JR, Goncalves D, Faria RM, Oliveira Jr ON (1995) Electrochemical response of poly (o-ethoxyaniline) films produced by different techniques. Electrochim Acta 40:1851-1855. https://doi.org/10.1016/0013-4686(95)00130-7

Mettai B et al. (2018) In situ chemical deposition of PPy/NDSA and PPy/DBSA layers on QCM electrodes: synthesis, structural, morphological and ammonia sensing performances study. J Polym Res 25:95. https://doi.org/10.1007/s10965-018-1500-z 
Nie G, Zhang Y, Xu J, Zhang S (2008) Low-potential facile electrosyntheses of free-standing poly (5methoxyindole) film with good fluorescence properties. J Electroanal Chem 622:121-127. https://doi.org/10.1016/j.jelechem.2008.05.008

Omastová M, Mičušík M (2012) Polypyrrole coating of inorganic and organic materials by chemical oxidative polymerisation. Chem Pap 66:392-414.https://doi.org/10.2478/s11696-011-0120-4

Qu K, Bai Y, Gao X, Deng M (2020) Application of poly (aniline-co-o-methoxyaniline) as energy storage material. Synth Met 262:116346. https://doi.org/10.1016/j.synthmet.2020.116346

Ren F, Zhou W, Du Y, Yang P, Wang C, Xu J (2011) High efficient electrocatalytic oxidation of formic acid at Pt dispersed on porous poly (o-methoxyaniline). Int J Hydrog Energy 36:6414-6421. https://doi.org/10.1016/j.ijhydene.2011.02.143

Sazou D, Deshpande PP (2017) Conducting polyaniline nanocomposite-based paints for corrosion protection of steel. Chem Pap 71:459-487.https://doi.org/10.1007/s11696-016-0044-0

Shinde VP, Patil PP (2013) A study on the electrochemical polymerization, characterization, and corrosion protection of o-toluidine on steel. J Solid State Electrochem 17:29-41. https://doi.org/10.1007/s10008-012$\underline{1847-8}$

Tian Y et al. (2017) A comprehensive study of electrochromic device with variable infrared emissivity based on polyaniline conducting polymer. Sol Energy Mater Sol Cells 170:120-126. https://doi.org/10.1016/j.solmat.2017.05.053

Tseghai GB, Mengistie DA, Malengier B, Fante KA, Van Langenhove L (2020) PEDOT: PSS-Based conductive textiles and their applications. Sensors 20:1881. https://doi.org/10.3390/s20071881

Wei Y, Focke WW, Wnek GE, Ray A, MacDiarmid AG (1989) Synthesis and electrochemistry of alkyl ringsubstituted polyanilines. J Phys Chem 93:495-499. https://doi.org/10.1021/j100338a095

Yalçınkaya S, Tüken T, Yazıcı B, Erbil M (2010) Electrochemical synthesis and corrosion behaviour of poly (pyrrole-co-o-anisidine-co-o-toluidine). Curr Apl 10:783-789. https://doi.org/10.1016/j.cap.2009.09.015

Yin X, Ding J, Zhang S, Kong J (2006) Enantioselective sensing of chiral amino acids by potentiometric sensors based on optical active polyaniline films. Biosens Bioelectron 21:2184-2187. https://doi.org/10.1016/j.bios.2005.10.010

Zhang Z, Wei Z, Zhang L, Wan M (2005) Polyaniline nanotubes and their dendrites doped with different naphthalene sulfonic acids. Acta Mater 53:1373-1379. https://doi.org/10.1016/j.actamat.2004.11.030 